\title{
Monoclonal Antibody MDX-220
}

National Cancer Institute

\section{Source}

National Cancer Institute. Monoclonal Antibody MDX-220. NCI Thesaurus. Code C2009.

A bispecific antibody containing a patented Trigger antibody and a humanized antibody that targets TAG-72. TAG-72 is overexpressed in a variety of cancers. 